\title{
PRECIFICAÇÃO DISCRIMINATÓRIA NO NOVO PARADIGMA TECNOLÓGICO DO MERCADO DE CONSUMO: A TUTELA DO CONSUMIDOR E A DEFESA DA CONCORRÊNCIA CONTRA PRÁTICAS ABUSIVAS COM O USO DE DADOS PESSOAIS
}

\author{
Guilherme Mucelin* \\ Laís Bergstein** \\ Sandra Regina Martini***
}

\begin{tabular}{l|l}
\hline RECEBIDO EM: & $\mathbf{2 2 . 1 0 . 2 0 2 0}$ \\
\hline APROVADO EM: & $\mathbf{2 9 . 1 1 . 2 0 2 0}$ \\
\hline
\end{tabular}

(n)

Doutorando em Direito da Universidade Federal do Rio Grande do Sul (UFRGS), mestre em Direito e especialista em Direitos Fundamentais e Direito do Consumidor pela mesma instituição, e especialista em Droit comparé et européen des contrats et de la consommation pela Université de Savoie Mont Blanc/UFRGS. Pós-graduando em Direito do Consumidor pela Universidade de Coimbra. Coordenador acadêmico do curso de especialização em "O Novo Direito do Consumidor", oferecido pela UFRGS. Pesquisador do grupo de pesquisa do Conselho Nacional de Desenvolvimento Científico e Tecnológico (CNPq) “Mercosul, Direito do Consumidor e Globalização”. Bolsista da Coordenação de Aperfeiçoamento de Pessoal de Nível Superior (Capes). E-mail: guilherme.mucelin@ufrgs.br

** Doutora em Direito do Consumidor e Concorrencial pela Universidade Federal do Rio Grande do Sul (UFRGS), mestra em Direito Econômico e Socioambiental pela Pontifícia Universidade Católica do Paraná (PUCPR). Alumni do Centro de Estudos Europeus e Alemães (CDEA). Pesquisadora vinculada aos grupos Mercosul, Direito do Consumidor (UFRGS) e Virada de Copérnico (UFPR). Coordenadora-adjunta do Programa de Mestrado Profissional do Complexo de Ensino Renato Saraiva (Faculdade Cers). Secretária-adjunta da Comissão Especial de Defesa do Consumidor do Conselho Federal da Ordem dos Advogados do Brasil. Advogada. E-mail: lais@dotti.adv.br

*** Doutora em Evoluzione dei Sistemi Giuridici e Nuovi Diritti pela Università Degli Studi di Lecce, Itália, mestra em Educação pela Pontifícia Universidade Católica do Rio Grande do Sul (PUCRS) e especialista em Programação e Gerência de Sistemas de Saúde pela Escola Nacional de Saúde Pública (Ensp). Coordenadora e professora do Mestrado em Direitos Humanos da UniRitter Laureate. Bolsista de produtividade 2 Conselho Nacional de Desenvolvimento Científico e Tecnológico (CNPq).E-mail: sandra.martini@uniritter.edu.br 
- RESUMO: O presente artigo propõe-se a analisar a relação entre perfilização dos consumidores e precificação discriminatória no novo paradigma digital e simbiótico do mercado de consumo, bem como as relações entre as normas de defesa do consumidor, da concorrência e de proteção de dados, as quais impõem limites legais a essas novas práticas, especialmente geoblocking e geopricing. Foi utilizado o método dedutivo, com abordagem documental, doutrinária, legislativa e jurisprudencial.

- palavras-chave: Precificação discriminatória; direito do consumidor e concorrência; dados pessoais.

\section{DISCRIMINATORY PRICING IN THE NEW TECHNOLOGICAL PARADIGM OF THE CONSUMER MARKET: CONSUMER PROTECTION AND COMPETITION PROTECTION AGAINST ABUSIVE PRACTICES WITH THE USE OF PERSONAL DATA}

- ABSTRACT: This article aims to analyze the relation between consumer profiling and discriminatory pricing in the new digital and symbiotic paradigm of the consumer market, as well as the relations among consumer protection, competition and data protection rules, which impose legal limits to these new practices, especially considering geoblocking and geopricing. The deductive method was used, with documental, doctrinal, legislative and jurisprudential approach.

- KEYWORDS: Discriminatory pricing; consumer and competition law; personal data.

\section{Introdução}

"In un tempo rivoluzionario per la forza pervasiva della tecnoscienza [...] tanto mutato torna, forte, l'apello ai diritti fondamentali” (RODOTÀ, 2012, P. 7).

O desenvolvimento tecnológico ${ }^{1}$ das últimas décadas, especialmente pela expansão do comércio eletrônico combinada com a capacidade de armazenamento, co-

1 “Assim, a técnica é aquilo que aproxima e distancia ao mesmo tempo. Acerca disso, a Metateoria do Direito Fraterno propõe, no seu projeto, uma inclusão, sem confins, em todos os direitos humanos dos consumidores atuais. Embora a técnica não se proponha ser excludente, muitas vezes opera como remédio, salvando e matando concomi- 
leta e tratamento de dados pessoais, propiciou profundas alterações nas dinâmicas mercadológicas, modificando a maneira como as relações de consumo são estabelecidas e desafiando alguns dos conceitos fundamentais de direito do consumidor, o que foi identificado por Miragem (2019) como o novo paradigma tecnológico no mercado de consumo.

Diversas novas situações emergem entre consumidores e fornecedores por conta do aumento das capacidades comerciais da utilização de big data que, em sentido contrário à evolução da sociedade de consumo cuja característica principal foi a massificação e a despersonalização das relações jurídicas (MARQUES, 2019), bem como dos processos de produção e fornecimento (MIRAGEM, 2020), hoje se concentram na hiperpersonalização, seja de produtos ou serviços oferecidos, seja de informações específicas relativas a determinado consumidor que passam a integrar o contrato de consumo, o que demanda, como nos lembra Rodotà (2012), um apelo mais forte aos direitos fundamentais ${ }^{2}$, tal qual a proteção do consumidor no direito brasileiro.

Contudo, o mercado de consumo como conhecemos hoje, integrado e conectado (BARBA, 2011, p. 43, 90 et seq.), não prescinde da massificação. As relações travadas em ambiente on-line - com um automatismo do fornecedor, oculto por telas de dispositivos conectados à internet, e do consumidor, resumido a cliques e dados - não significam, necessariamente, a despersonalização das relações de consumo, já que, pela natureza da funcionalidade do meio, com o incremento de tecnologias de perfilização dos consumidores, o que se tem é justamente o inverso, inclusive no campo contratual $^{3}$.

Refira-se, os perfis criados com base nos dados pessoais são de extrema relevância aos fornecedores - inclusive econômica -, já que assim lhes é dada a oportunidade de melhor conhecer seus consumidores atuais e potenciais e quase todos os aspectos de sua vida pessoal, para que assim consigam valorar e antever comportamentos, tanto no aspecto positivo, como a antecipação de necessidades ou sugestões de bens de con-

tantemente, mas pode ser, concomitantemente, um fator de incremento da potência, da possibilidade de inclusão e da realização de objetivos e metas que melhorem a qualidade de vida dos cidadãos mais vulneráveis”(MARTINI, 2017).

2 Constituição Federal da República Federativa Brasileira de 1988: “Art. $5^{\circ}$. Todos são iguais perante a lei, sem distinção de qualquer natureza, garantindo-se aos brasileiros e aos estrangeiros residentes no País a inviolabilidade do direito à vida, à liberdade, à igualdade, à segurança e à propriedade, nos termos seguintes: XXXII - o Estado promoverá, na forma da lei, a defesa do consumidor".

3 Sobre o tema, ver Południak-Gierz (2019). Trata-se de interessante estudo sobre os algoritmos de precificação a partir de uma análise do direito privatístico da União Europeia e da Polônia, especialmente no que toca aos métodos de contratação por adesão "repersonalizados". 
sumo, como no negativo, quando sua utilização viabiliza práticas abusivas ou acomete desvantagens aos consumidores, de modo a dificultar-lhes ou até mesmo excluí-los do mercado de consumo.

Uma das importantes questões desse cenário digital ao direito do consumidor é a precificação discriminatória, conceituada em linhas gerais pela Organização para a Cooperação e Desenvolvimento Econômico(OCDE) como a cobrança de diferentes preços a diferentes consumidores (ou o mesmo consumidor) por duas unidades do mesmo produto ou duas prestações do mesmo serviço, sem que essa diferença de valores reflita alterações em algum dos custos da transação, com a finalidade de fazer que o consumidor pague tanto quanto esteja disposto a gastar por determinado produto ou serviço (BOURREAU; STREEL, 2018).

Preços diferenciados não são uma prática nova no mercado de consumo. A novidade é justamente a utilização do perfil do consumidor, que carrega consigo dados de localização, etnográficos, de gostos e preferências, de comportamento de compras on-line e uma infinidade de cruzamentos que resultam em métricas de precificação opacas, obscuras e, muitas vezes, discriminatórias. O objetivo do presente artigo é, portanto, verificar se essa prática encontra morada no ordenamento jurídico brasileiro ou, ao contrário, há o estabelecimento de limites legais, especialmente pelos prismas do Código de Defesa do Consumidor (CDC), da defesa da concorrência e da Lei Geral de Proteção de Dados Pessoais (LGPD), sem prejuízo de análise de demais legislações pertinentes.

Nesse sentido, o presente trabalho, pautado no método dedutivo, com abordagem documental, doutrinária, legislativa e jurisprudencial, divide-se em duas partes. A primeira tem por função analisar os enlaces dos desenvolvimentos tecnológicos no mercado de consumo, especialmente a prática de perfilização e sua relação com discriminação de preços, em especial pelas práticas de geopricing e geoblocking, para, na segunda parte, analisar a possível abusividade na ótica do microssistema de proteção do consumidor e a insuficiência dos critérios permissivos presentes na LGPD para o tratamento de dados pessoais dos consumidores para essa finalidade, evidenciando, ao final, a convergência dos dois diplomas para a tutela efetiva do consumidor no consumo simbiótico. 


\section{Perfilização dos consumidores e discriminação de preços no mercado de consumo: o caso do geoblocking e do geopricing}

A criação de perfis pode ocorrer em uma ampla variedade de contextos com finalidades de aplicação distintas. Essa técnica é utilizada desde investigações criminais a pesquisas de mercado, de cálculos matemáticos à engenharia da computação, de aplicativos de saúde pessoal e informações genéticas à medicina preventiva, até mesmo servindo para auxiliar a elaboração de políticas públicas (HILDEBRANDT, 2008, p. 17).

Perfilização, então, pode ser definida como o processo tecnológico que se utiliza de algoritmos para a descoberta de correlações entre diferentes bases de dados, a fim de identificar e de representar uma pessoa em determinado grupo, com o objetivo de individualizá-la (perfis individuais) ou segmentá-la em grupos ou categorias menores (HILDEBRANDT, 2008, p. 19), prestando classicamente para dividir o mercado em “fatias" (KOTLER; KELLER, 2012, p. 228) e, atualmente, com os avanços nos níveis de precisão do processo de criação de perfis, bem como com as decisões automatizadas, para hiperpersonalizar o consumo em todas as suas fases, da produção ao oferecimento ao público consumidor. Nesse amplo cenário, nossa análise focará as práticas de precificação diferenciada.

Para que os fornecedores possam elaborar preços personalizados de acordo com cada consumidor individualmente considerado, uma camada refinada de tecnologias - entre as quais a machine learning e a inteligência artificial - embasadas em coleta, tratamento e processamento de dados pessoais está sendo aplicada às práticas comerciais, especialmente no que toca à oferta e ao marketing direcionado 4 . Tal é parte estratégica de uma segmentação mercadológica cada vez mais acurada, cuja finalidade é oferecer produtos e serviços de acordo com as preferências de cada um, mudando layouts, informações e atributos da relação de consumo em tempo real (MIK, 2016, p. 22-24).

Perfilização e decisões automatizadas, então, andam juntas nas novas dinâmicas do mercado de consumo simbiótico ${ }^{5}$, o qual é caracterizado pelo esmaecimento da li-

4 Sobre a transição do marketing tradicional ao marketing digital, ver Kotler, Kartajaya e Setiawan (2017).

5 Conforme sinalizam Marques e Miragem (ahead of print), a simbiose no consumo decorre justamente da interação entre o "real" e o "virtual", entre software e hardware: "uma nova fase do consumo, não exatamente só de serviços digitais, mas de produtos inteligentes ('smarts objects'), bens que apresentam uma nova simbiose entre produto e serviço, entre hardware e software, bens que incluem um serviço ou conteúdo digital ('embedded digital content') até chegar na Internet das Coisas". 
nha divisória conceitual entre comércio eletrônico e comércio analógico, no sentido de que o elo a unir ambas as formas de consumo passa a ser os dados pessoais, que residem por excelência no ciberespaço e que podem ser vendido para $n$ fornecedores (BONATTI; CISTERNAS, 2020, p. 751). Tanto on-line quanto off-line, o consumo será pautado pelos dados, por escores e por séries de informações que serão agregadas aos perfis individuais. Percebe-se, assim, que perfilização não pode ser analisada isoladamente, pois está relacionada a três fatores (EUROPEAN CONSUMER ORGANIZATION, 2018, p. 9): 1. deve ser uma forma de tratamento de dados automatizada ${ }^{6}, 2$. deve ser realizada sobre os dados pessoais ou estar equiparada a $\operatorname{eles}^{7}$ e 3 . seu objetivo deve ser avaliar aspectos individuais de uma pessoa singular.

Essa interdependência foi bem visualizada no Regulamento Geral sobre a Proteção de Dados da União Europeia (RGPD). De um lado, o art. $4^{\circ}$ (4) do referido documento conceitua definição de perfis como quaisquer formas de tratamento automatizado de dados pessoais que os utilizem para avaliar aspectos pessoais de determinada pessoa, especialmente para analisar ou prever características relacionadas com desempenho profissional, situação econômica, saúde, preferências pessoais, interesses, fiabilidade, comportamento, localização ou deslocações ${ }^{8}$; de outro lado, o art. 22 (1) traz o direito do titular de dados "de não ficar sujeito a nenhuma decisão tomada exclusivamente com base no tratamento automatizado, incluindo a definição de perfis, que produza efeitos na sua esfera jurídica ou que o afete significativamente de forma similar" (grifo nosso).

6 Aqui existe certa divergência de interpretação. Tanto o RGDP quanto a LGDP trazem direito à revisão e supervisão de um ser humano nas decisões automatizadas que intervenham nos direitos ou nos interesses dos titulares, desde que ela seja totalmente automatizada, o que afastaria a aplicação dos dispositivos em comento se houvesse alguma intervenção humana. Lançam oportuno entendimento as Guidelines on Automated individual decision-making and Profiling for the purposes of Regulation 2016/679 da União Europeia, que esclarecem que a intervenção humana deve ser significativa e não apenas um gesto simbólico (DATA PROTECTION WORKING PARTY, 2017, p. 9).

7 LGDP: “Art. 12. [...]. $\$ 2^{\circ}$ Poderão ser igualmente considerados como dados pessoais, para os fins desta Lei, aqueles utilizados para formação do perfil comportamental de determinada pessoa natural, se identificada”. Nesse sentido, acertada a posição da Lei, haja vista que o Grupo de Trabalho de Proteção de Dados Pessoais de Macau, desde 2014 já alertava sobre a facilidade de identificação de determinada pessoa, mesmo a partir de dados anonimizados.

8 RGDP: “Art. 4․ Definições. Para efeitos do presente regulamento, entende-se por: 4) "Definição de perfis”, qualquer forma de tratamento automatizado de dados pessoais que consista em utilizar esses dados pessoais para avaliar certos aspetos pessoais de uma pessoa singular, nomeadamente para analisar ou prever aspetos relacionados com o seu desempenho profissional, a sua situação económica, saúde, preferências pessoais, interesses, fiabilidade, comportamento, localização ou deslocações”.

9 RGDP: “Art. 22. Decisões individuais automatizadas, incluindo definição de perfis. 1. O titular dos dados tem o direito de não ficar sujeito a nenhuma decisão tomada exclusivamente com base no tratamento automatizado, incluindo a definição de perfis, que produza efeitos na sua esfera jurídica ou que o afete significativamente de forma similar". 
A LGPD brasileira, muito embora não tenha definido juridicamente perfilização nem decisões automatizadas, tratou sobre o assunto indissociando-os, na esteira do regulamento europeu. $\mathrm{O}$ art. 20 da lei, que trata sobre o direito do titular à revisão no que toca a essas decisões de modo geral, incluiu no mesmo rol as "decisões destinadas a definir o seu perfil pessoal, profissional, de consumo e de crédito ou aspectos de sua personalidade ${ }^{\$ 10}$, mas nada trouxe acerca de conceitos.

Para reforçar a utilidade e o alcance social da norma, de forma a não prejudicar a proteção pretendida pela LGDP aos titulares dos dados, deve-se preencher essa lacuna normativa. Assim é que foi proposto, pelo senador Styvenson Valentim, o Projeto de Lei n. 4.496/2019 do Senado Federal, que pretende adicionar ao art. $5^{\circ}$ da LGDP, o qual trata sobre os conceitos jurídicos de termos tecnológicos, o inciso XX. De lege ferenda, traz-se a definição de decisão automatizada: relaciona-se ao processo de escolha, aprovação, classificação ou rejeição, atribuição de nota, medida, pontuação ou escore, de cálculo de risco, probabilidade ou outro semelhante, que se utiliza de regras, cálculos, instruções, algoritmos, estatística, inteligência artificial, aprendizado de máquina ou outra técnica computacional.

De modo geral, à medida que essas técnicas ficam mais sofisticadas, uma série de dados é agregada ao perfil, como dados biográficos aleatórios, padrões de compra on-line e off-line, padrões de navegação (a exemplo dos cookies e da velocidade do clicar na tela), círculos de contatos em redes sociais, opções de entretenimento, livros lidos ou filmes vistos, informações genéticas e todo e qualquer dado aparentemente inofensivo, mas que, juntos, revelam características muito próprias que têm o potencial de serem aproveitadas economicamente ${ }^{11}$. Sumpter (2019, p. 38-39), quando analisa redes sociais, sinaliza que "cada 'curtida' fornece um pouco de informação sobre uma pessoa e que um acúmulo de 'curtidas' permite que seu algoritmo faça conclusões confiáveis", sendo necessárias "de 40 a 100 dimensões ${ }^{12}$ para nos classificar com precisão”. No mesmo caminho, um interessante estudo aponta que o número suficiente

10 LDGP: “Art. 20. O titular dos dados tem direito a solicitar a revisão de decisões tomadas unicamente com base em tratamento automatizado de dados pessoais que afetem seus interesses, incluídas as decisões destinadas a definir o seu perfil pessoal, profissional, de consumo e de crédito ou os aspectos de sua personalidade. (Redação dada pela Lei n. 13.853, de 2019)".

11 Nesse sentido, ver: MARQUES, C. L.; MUCELIN, G., 2020.

12 Para o autor, dimensões são categorias que variarão conforme o algoritmo utilizado. No experimento que o autor realizou, o algoritmo determinou 13 dimensões em relação às fotos de pessoas em redes sociais, que iam desde fotos somente relacionadas à vida pessoal até o outro extremo, imagens relacionadas somente à vida profissional. 
de “curtidas” para que um dispositivo conheça melhor o usuário do que a pessoa que habita na mesma residência está entre 150 e 200 (YOUYOU; KOSINSKI; STILLWEL, 2015, p. 1038).

Assim se pode estabelecer que a qualidade da relação entre consumidores e fornecedores muda, já que, segundo Ford (2000, p. 1575), o perfil individual funcionaria como o sósia do consumidor, não existindo diferenças cruciais, aos olhos do mercado, entre o perfil e o consumidor "real” (BROWNSWORD, 2017, p. 181), justo porque, na medida em que preferências e hábitos da vida privada forem revelados, conclusões acuradas sobre sexo, idade, condição sexual, estado de saúde, de renda e até mesmo de ânimo comporão estratégias de fornecimento. Em outros termos, o fornecedor amoldará produtos, serviços e condições contratuais específicas em tempo real para combinar com vulnerabilidades e necessidades específicas dos consumidores previstas pelos algoritmos, a fim de melhor atender aos interesses da cadeia de fornecimento (MIK, 2016, p. 22-24) e não necessariamente aos dos sujeitos que se engendram nessas relações.

O problema, nesses casos, além da privacidade, é o aproveitamento econômico, ou melhor, a mercantilização das vulnerabilidades de acordo com os interesses convenientes à cadeia de fornecimento. Cabe frisar: decisões automatizadas e perfilização, de maneira geral, servem aos fornecedores para o estabelecimento de relações de consumo que lhes tragam maiores vantagens, de modo, por exemplo, a ofertar preços diferenciados a diferentes consumidores pelo mesmo bem de consumo, potencialmente representando a exclusão de oportunidades e de acessos no mercado.

Sabe-se que o tratamento discriminatório de preços aos consumidores fomentado pelo uso de dados pessoais é recorrente no mercado, embora ainda não se possa precisar qual a sua real extensão (ORGANISATION FOR ECONOMIC CO-OPERATION AND DEVELOPMENT, 2018). A identificação e a percepção dos efeitos da discriminação de preços $^{13}$ representam um dos grandes desafios para a efetividade da tutela dos consumidores e da defesa da concorrência ${ }^{14}$. Ea questão extrapola as fronteiras nacionais (cf. STUCKE; GRUNES, 2016). Diferentemente das situações nas quais a discriminação

\footnotetext{
13 Distingue-se a diferenciação de preços - lícita nos termos da Lei n. 13.455, de 26 de junho de 2017, por exemplo - da discriminação de preços. A Constituição da República veda qualquer forma de discriminação (arts. $3^{\circ}$, IV; 5o, XLI; 227, entre outros) (BERGSTEIN; TRAUTWEIN, 2019).

14 Sobre a defesa da concorrência e seu papel para a tutela do consumidor, ver Pfeiffer (2015).
} 
PRECIFICACÃO DISCRIMINATÓRIA NO NOVO PARADIGMA TECNOLÓGICO DO MERCADO DE CONSUMO: A TUTELA DO CONSUMIDOR E A DEFESA DA CONCORRÊNCIA CONTRA PRÁTICAS ABUSIVAS COM O USO DE DADOS PESSOAIS

ocorre em razão da etnia ${ }^{15}$, do gênero ${ }^{16}$, da idade ou da condição social ${ }^{17}$, o enfoque no comércio eletrônico passa a ser as práticas de geoblocking e geopricing, ou seja, a oferta ou a precificação diferenciadas com base na localização e no padrão de compras do consumidor: sua sensibilidade ou não ao preço.

No contexto da economia digital, acentua-se, por meio das práticas comerciais do geopricing e do geoblocking, a diferenciação da oferta de produtos e serviços às pessoas de acordo com a sua localização ou com o seu grau de sensibilidade ao preço de produtos e serviços. Essa diferenciação pauta-se tanto pela sua disponibilidade financeira quanto pela necessidade de consumir, ou seja, pela essencialidade da contratação. Essas práticas comerciais podem, por vezes, configurar ilícitos.

Perceber a ocorrência de tal prática abusiva é um grande desafio. Se a habitualidade de algumas práticas abusivas faz que a ilegalidade passe despercebida no dia a dia do consumidor brasileiro, com o avanço tecnológico, a percepção e comprovação de práticas comerciais discriminatórias tornaram-se ainda mais difíceis. Com o avanço da internet das coisas, qualquer objeto conectado pode ser um potencial coletor de dados e informações pessoais.

O jornal The New York Times (MAHESHWARI, 2018) denunciou o uso de dados obtidos por meio de aplicativos de medição de febre para a distribuição de anúncios publicitários por região dos Estados Unidos. As informações sobre a localidade dos

15 “Separados, reconheceu o Tribunal, jamais seriam iguais", lembrou Ruth Bader Ginsburg, ministra da Suprema Corte dos Estados Unidos, em discurso proferido na África do Sul, em 2006, no qual relatou a evolução histórica da compreensão do tema da discriminação em seu país: "a Constituição dos Estados Unidos tem quase 220 anos e não contém disposição expressa contrária à discriminação com base no gênero. A jurisprudência de proteção igualitária nos Estados Unidos envolve a interpretação do comando de que autoridades governamentais não podem negar às pessoas 'a igual proteção das leis'. Essas palavras, inseridas na Constituição de 1868, foram interpretadas de forma restrita, mas ao longo do tempo elas provaram ter potencial de crescimento. Nos anos 1890, a Suprema Corte dos Estados Unidos disse que a segregação racial, determinada pela lei estadual, era compatível com o princípio de proteção igualitária da Constituição. Por volta da metade do século XX, a Suprema Corte reconheceu o quão errado estava aquele julgamento. Separados, reconheceu o Tribunal, jamais seriam iguais. No entanto, até 1971, a Corte rejeitou a queixa de toda mulher a que foi negada proteção igual por uma lei estadual ou federal. Naquele ano, em 1971, a Corte guinou em uma nova direção. Os ministros começaram a responder favoravelmente aos argumentos invocados por advogados que demandavam uma interpretação mais dinâmica do princípio da interpretação igualitária, a qual serviria melhor àquela evoluída sociedade dos Estados Unidos” (tradução nossa).

16 No âmbito da União Europeia, organização internacional precursora em termos de proteção dos seus consumidores, o Conselho da Comunidade Europeia aprovou a Diretiva n. 2004/113/CE, de 13 de dezembro de 2004, que aplica o princípio de igualdade de tratamento entre homens e mulheres no acesso a bens e serviços e seu fornecimento. "Art. 10: A presente directiva tem por objeto estabelecer um quadro para combater à discriminação em função de sexo no acesso a bens e serviços e seu fornecimento, com vistas a concretizar nos Estados-Membros, o princípio da igualdade de tratamento entre homens e mulheres".

17 Caso paradigmático de discriminação de consumidores foi o impedimento de acesso aos jovens que participaram dos movimentos chamados de "rolezinhos", prática dos centros comerciais que fere a igualdade de tratamento prevista constitucionalmente, seja de forma geral como direito fundamental, seja de forma específica como direito do consumidor (FREITAS FILHO; COSTA, 2017). 
usuários do aplicativo que apresentavam sintomas de gripes e resfriados foram compartilhadas com o setor farmacêutico. O resultado foi o aumento significativo dos investimentos em publicidade dessas regiões pelas empresas beneficiadas com a coleta $\mathrm{e}$ o compartilhamento de tais informações dos consumidores.

Pelo que se percebe desse exemplo, a fonte dessas informações pode ser qualquer dispositivo utilizado no dia a dia. Carros, fechaduras, roupas, utensílios de cozinha, geladeiras, televisores, smartphones, brinquedos, enfim, todos os equipamentos eletrônicos que nos cercam estão sendo adaptados para coletar, selecionar e armazenar dados pessoais. Ea coleta começa cada dia mais cedo. A boneca chamada Hello Barbie, produzida pela Mattel, por exemplo, é integrada com sistemas de reconhecimento de fala e de tecnologia de inteligência de conversação, que lhe permite interagir com a criança e, naturalmente, arquivar em banco de dados as informações por ela ingenuamente fornecidas (CARNETI, 2015), sem falar nas possibilidades de invasões por hackers ${ }^{18}$.

Não raras vezes, a comprovação somente é possível por causa do oferecimento de denúncias por prepostos ou até mesmo pela concorrência no setor.

\section{A defesa do consumidor e da concorrência contra o uso indevido de dados pessoais}

As Guidelines for Consumer Protection das Nações Unidas, atualizadas em 2015, orientam os Estados-membros a, se necessário, rever as políticas de proteção ao consumidor para acomodar as características especiais do comércio eletrônico e garantir que os consumidores e as empresas estejam informados e conscientes dos seus direitos e obrigações no mercado digital (UNITED NATIONS CONFERENCE ON TRADE AND DEVELOPMENT, 2016).

A concentração de informações sobre as características pessoais do consumidor resulta em uma posição de poder do fornecedor (SEARS, 2019,p. 10), a qual lhe permite

18 Por conta disso, outra boneca, mas com as mesmas características, chamada de Cayla, foi proibida em alguns países (MIRAGEM, 2017). Na Alemanha, o Bundesnetzagentur, em 2017, responsável pelas telecomunicações naquele país, alertou sobre possíveis falhas de privacidade na boneca Cayla, além de problemas em relação à segurança, como o fato de um usuário na mesma rede do brinquedo poder ter acesso e se conectar a ele e transmitir/receber dados sem o consentimento dos pais, transformando a boneca em uma “espiã", possibilitando assim o acesso à criança ou ao adolescente por pessoas mal-intencionadas. Pela lei alemã, não só sua comercialização foi proibida, mas também sua posse é considerada para fins de direito penal, pois classificou a boneca como dispositivo de espionagem ilegal (BOLGER, 2017). 
pressionar o consumidor, mesmo sem recurso ou ameaça de recurso à força física ${ }^{19}$. O processamento dos dados constitui uma vantagem que, dependendo de como utilizado, pode limitar significativamente a capacidade de o consumidor tomar uma decisão esclarecida, como resultado de uma influência indevida.

Ocorre que a identificação de práticas abusivas envolvendo a captura e o uso não autorizados de dados pessoais não é simples. Além da grande quantidade de informações disponibilizada na rede (big data), os termos de consentimento para captura e armazenamento de dados pessoais são, geralmente, bastante genéricos, o que obstaculiza a identificação do desvio de finalidade no uso da informação. A constatação e coibição de tais práticas perpassam, nesse contexto, tanto a atuação dos órgãos e das associações internacionais de proteção e defesa dos consumidores no controle dessas práticas comerciais $^{20}$ quanto o oferecimento de denúncia pelos concorrentes. Um dos mais recentes exemplos no mercado brasileiro foi o caso da Decolar.com(FRAZÃO, 2018), que trouxe a lume o uso de inteligência artificial para diferenciar preços aos consumidores pelo mesmo item.

A identificação das práticas ocorreu, naquele caso, por causa da representação por outra empresa que atua no mercado de hospedagem como intermediária entre estabelecimentos hoteleiros e consumidores, a qual alegou que a denunciada "estaria oferecendo reservas a preços diferentes, a depender da localização do consumidor, identificado por intermédio do Internet Protocol - IP (identificação única para cada aparelho com acesso à Internet, conectado a uma rede)", o que configuraria o geopricing, bem como "ocultando a disponibilidade de acomodações a consumidores brasileiros, em favor de consumidores estrangeiros, conduta denominada geoblocking” (BRASIL, 2020a).

Subsidiado pela Nota Técnica n. 92/2018 (BRASIL, 2020a), que constatou a violação aos arts. $4^{\circ}$, caput, incisos I e III, $6^{\circ}$, incisos II, III e IV, e 39, incisos II, IX e X do CDC, o Departamento de Proteção e Defesa do Consumidor (DPDC), sob a diretoria da Dra. Ana Carolina P. Caram Guimarães, aplicou a sanção administrativa de multa à Decolar.

19 Um bom exemplo pode ser visto no caso da Cambridge Analytica, empresa que manipulou as eleições dos Estados Unidos e que se utiliza de "microtargeting comportamental" a partir de dados pessoais do Facebook com o fim de organizar modelos preditivos que revelam os "gatilhos" psicológicos básicos de cada pessoa e influenciar, dessa maneira, o processo de eleição (KAISER, 2020, p. 195). Sobre uma possível vulnerabilidade por manipulação, que teve como centro de análise o discurso retórico de grandes empresas da economia do compartilhamento, ver: MUCELIN, 2020, em especial o primeiro capítulo.

20 A Consumers International (2016, tradução nossa) há anos reconheceu que "está cética quanto ao fato de a proteção ao consumidor, como atualmente concebida e implementada, ser suficiente para defender os direitos do consumidor em um ambiente em que aparelhos e dispositivos em nossas casas, nossos veículos e nossas pessoas se tornam mais inteligentes e conectados". 
com Ltda., empresa consolidada no setor de turismo, pelo uso de dados de localização do consumidor para “a diferenciação de preço de acomodações e negativa de oferta de vagas, quando existentes” (BRASIL, 2018b), práticas reconhecidas como abusivas e discriminatórias. A denunciada negou as acusações ${ }^{21}$, e a questão foi submetida à apreciação do Poder Judiciário ${ }^{22}$ sob segredo de justiça (CAMURÇA, 2020, p. 131) para preservação dos interesses comerciais diante da necessidade de a requerida, quando de sua defesa técnica, revelar o modus operandi e seu modelo de negócio. A ação ainda não transitou em julgado, mas o caso já foi amplamente noticiado em diversos meios de comunicação ("DECOLAR É MULTADA EM R\$ 7,5 MILHÕES POR DIFERENCIAR PREÇOS A CONSUMIDOR”, 2018; “DECOLAR.COM É MULTADA EM R\$ 7,5 MILHÕES POR DIFERENCIAÇÃO DE PREÇO”, 2018), e a exposição do nome da empresa foi negativa no mercado de consumo brasileiro.

Conforme pontua Ana Frazão (2018), a legislação antitruste também estabelece a ilicitude da abusiva discriminação de adquirentes de bens ou serviços por meio de fixação diferenciada de preços ou da recusa de venda em consonância com os usos e costumes comerciais. O art. 36, $\$ 3^{\circ}$, “d”, X, da Lei n. 12.529/2011 estabelece expressamente como infração à ordem econômica a prática mercantil consistente em discriminar adquirentes ou fornecedores de bens ou serviços por meio da fixação diferenciada de preços, ou de condições operacionais de venda ou prestação de serviços (BRASIL, 2011).

Também com base na Lei n. 12.529/2011, o Superior Tribunal de Justiça consolidou o entendimento de que "a discriminação de adquirentes ou fornecedores de bens ou serviços mediante imposição diferenciada de preços, bem como a recusa à venda de bens ou à prestação de serviços em condições de pagamento corriqueiras na prática comercial (art. 36, X e XI)” configura infração à ordem econômica “a despeito da existência de culpa ou de ocorrência de efeitos nocivos” (BRASIL, 2015).

A precificação diferenciada somente se admite excepcionalmente, por razões justificadas. Ary Solon (1996) sugere algumas das peculiaridades da contratação que au-

21 Em nota, a Decolar informou que não pratica geopricing em seu modelo de negócios da companhia, que opera com transparência, honestidade, integridade e respeito aos seus clientes, e, principalmente, em conformidade com as leis, as normas e os regulamentos aplicáveis em todos os países em que atua. A empresa opera em cada país por meio de um site local, que não faz discriminação de preços nacionais ou estrangeiros. Sobre a acusação de manipular as reservas e a disponibilidade de vagas em hotéis, discriminando o consumidor brasileiro em favor do argentino, a companhia reforça que se trata de um questionamento errôneo e inverídico, uma vez que são comparados mercados distintos (Argentina e Brasil), sujeitos a legislações, regulamentos e precificação diferentes. Ver ainda a síntese da defesa da Decolar em Brasil (2020a).

22 Com o ajuizamento, pelo Ministério Público do Estado do Rio de Janeiro (MPRJ), da Ação Civil Pública n. 001805127.2018.8.19.0001, que tramita perante a $7^{\text {a }}$ Vara Empresarial do Rio de Janeiro (BRASIL, 2020b). 
torizariam uma diferenciação de preços: 1 . a contemporaneidade das diversas vendas, 2. a similaridade dos produtos ou sua diferença física, 3. a categoria de compradores (grandes revendedores, lojas de descontos ou varejistas), 4. a localização geográfica do comprador (que pode importar no aumento de custos de transportes e seus riscos), 5. a quantidade adquirida, 6 . serviços prestados pelos adquirentes na promoção dos produtos, e outros muitos fatores justificadores de diferenciação de preços.

$\mathrm{Na}$ Europa, os dias que antecederam a vigência da regulamentação da União Europeia de proteção de dados pessoais foram marcados por inúmeros e-mails contendo explicações sobre as políticas de uso de sistemas de e-mail e de armazenamento. No Brasil, em que pese o fato de a nova legislação ter uma base constitucional sólida ${ }^{23}$, o início da vigência da Lei n. 13.709/2018 (LGPD), publicada em 15 de agosto de 2018, foi bastante tumultuado ${ }^{24}$.

Na prática forense, percebe-se que, a despeito do reconhecimento do direito à autodeterminação informativa (art. $2^{\circ}$, II, LGPD), atribuindo ao titular dos dados pessoais o controle sobre o uso e o compartilhamento das suas informações, grande parte dos fornecedores não está preparada para o cumprimento da lei. Essa diretriz determina modificações profundas em diversos negócios, exigindo a implementação de mecanismos efetivos de segurança das informações e de conformidade com a legislação, acentuando o controle sobre um ambiente até então pouco ou quase nada regulado. E as sanções pelo descumprimento são graves ${ }^{25}$.

23 Encontra seus alicerces principalmente nos princípios de tutela da dignidade da pessoa humana (art. $1^{\circ}$, III, da Constituição Federal), de inviolabilidade da intimidade, da vida privada, da honra e da imagem das pessoas e de proteção ao sigilo de seus dados (art. $5^{\circ}, \mathrm{X}$ e XII, da Constituição Federal).

24 Conforme redação dada pela Lei n. 13.853, de 2019, os arts. 55-A, 55-B, 55-C, 55-D, 55-E, 55-F, 55-G, 55-H, 55-I, 55-J, 55-K, 55-L, 58-A e 58-B da LGPD entraram em vigor no dia 28 de dezembro de 2018. Os arts. 52, 53 e 54, incluídos pela Lei n. 14.010/2020, entrarão em vigor em $1^{\circ}$ de agosto de 2021. A Medida Provisória n. 959/2020 e a respectiva Lei de Conversão, contudo, estabeleceram regras distintas para a vigência da maior parte da LGPD, tema ainda em discussão.

25 As sanções administrativas aplicáveis isolada ou cumulativamente pela Autoridade Nacional são previstas no art. 52 da LGPD e poderão incluir uma multa por infração de até $2 \%$ do faturamento da pessoa jurídica, grupo ou conglomerado no Brasil no seu último exercício, podendo atingir até R\$ 50 milhões (art. 52, II, da LGPD). Também é prevista uma sanção de shaming, ou seja, de publicização da infração após a apuração e a confirmação da sua ocorrência por meio de processo administrativo (art. 52, IV, da LGPD). As sanções da LGPD não excluem as previstas em outras leis, como a que define o crime de concorrência desleal em desfavor de outras empresas do setor quando os dados obtidos ilegalmente forem utilizados para oferta de produtos ou serviços, gerando uma vantagem competitiva no setor. Delito previsto no art. 195, XI e XII, da Lei n. 9.279/96: “Art. 195. Comete crime de concorrência desleal quem: [...] XI - divulga, explora ou utiliza-se, sem autorização, de conhecimentos, informações ou dados confidenciais, utilizáveis na indústria, comércio ou prestação de serviços, excluídos aqueles que sejam de conhecimento público ou que sejam evidentes para um técnico no assunto, a que teve acesso mediante relação contratual ou empregatícia, mesmo após o término do contrato; XII - divulga, explora ou utiliza-se, sem autorização, de conhecimentos ou informações a que se refere o inciso anterior, obtidos por meios ilícitos ou a que teve acesso mediante fraude. [...] Pena - detenção, de 3 (três) meses a 1 (um) ano, ou multa”. 
A limitação legal do valor da multa que pode ser aplicada pelos órgãos de defesa do consumidor prevista no art. 57, parágrafo único, do $\mathrm{CDC}^{26}$ pode, em algumas circunstâncias, mitigar o fator de desestímulo às práticas comerciais abusivas. Por sua vez, a publicização da imposição de sanções administrativas pode ensejar um abalo à honra objetiva e, com ele, prejuízos imensuráveis à empresa. Além disso, a necessidade de revelar a forma de funcionamento do negócio no âmbito de um processo judicial, na fase de instrução probatória, é fator de risco para as empresas sob a perspectiva concorrencial. Essas preocupações devem servir como incentivo à manutenção de políticas de governança e compliance bastante rígidas, que priorizem uma perspectiva conservadora na interpretação e na observância das normas jurídicas, a fim de reduzir os riscos de exposição da marca (BERGSTEIN, 2020).

No campo da propriedade industrial, o desenvolvimento de marcas de certificação pode contribuir para o incremento da segurança das contratações. A marca de certificação é usada para atestar a conformidade de um produto ou serviço com normas, padrões ou especificações técnicas determinados, notadamente quanto à qualidade, à natureza, ao material utilizado e à metodologia empregada (art. 123, inciso II, da Lei n. 9.279/96, Lei de Propriedade Industrial - LPI).

A marca de certificação possui finalidade distinta das marcas de produto e de serviço; o seu objetivo principal é informar ao público que o produto ou serviço distinguido pela marca está de acordo com normas ou padrões técnicos específicos. Nos moldes da LPI, a marca de certificação deve ser utilizada somente por terceiros que o titular autorize como forma de atestar a conformidade do produto ou serviço aos requisitos técnicos, ou seja, destina-se apenas à certificação de terceira parte. Uma vez cumpridos os requisitos, o interessado está apto a incorporar em seu produto/serviço a marca de certificação do titular do registro no Instituto Nacional de Propriedade Industrial (Inpi).

Uma marca dessa natureza não substitui nem dispensa os selos de inspeção sanitária ou o cumprimento de qualquer regulamento ou norma específica para produto ou serviço estabelecidos pela legislação vigente, mas pode ser um passo importante na

\footnotetext{
26 "Art. 57. A pena de multa, graduada de acordo com a gravidade da infração, a vantagem auferida e a condição econômica do fornecedor, será aplicada mediante procedimento administrativo, revertendo para o Fundo de que trata a Lei no 7.347, de 24 de julho de 1985, os valores cabíveis à União, ou para os Fundos estaduais ou municipais de proteção ao consumidor nos demais casos. (Redação dada pela Lei no ${ }^{\circ}$ 8.656, de 21.5.1993) Parágrafo único. A multa será em montante não inferior a duzentas e não superior a três milhões de vezes o valor da Unidade Fiscal de Referência (Ufir), ou índice equivalente que venha a substituí-lo. (Parágrafo acrescentado pela Lei no 8.703 , de 6.9.1993).”
} 
garantia de conformidade com elevados padrões de segurança no que concerne ao uso de dados pessoais.

\section{Considerações finais}

Ludwig Krämer (2019, p. 24) afirma que o “verdadeiro nascimento” do direito do consumidor na então chamada Comunidade Europeia ocorreu em outubro de 1972, por ocasião da primeira reunião dos chefes de Estado e de governo dos nove países integrantes da Comunidade Europeia em Paris, quando definiram os novos domínios de ação comunitária (referentes às políticas regional, ambiental, social, energética e industrial).

O documento final desse encontro, com notável atualidade, declara o seguinte:

O crescimento econômico não é um fim em si mesmo. Seu primeiro objetivo deve ser o de reduzir as disparidades nas condições de vida. Deve ocorrer com a participação de todos os agentes sociais. Isso deve resultar em uma melhoria na qualidade de vida e nos padrões de vida. Como convém ao gênio da Europa ${ }^{27}$, será dada especial atenção aos valores intangíveis e à proteção do meio ambiente, para que o progresso seja realmente colocado a serviço da humanidade ${ }^{28}$.

Em 1973, a Comissão das Nações Unidas sobre os Direitos do Homem deliberou que o consumidor deveria gozar de quatro direitos fundamentais: 1 . o direito à segurança; 2. o direito à informação sobre produtos, serviços e suas condições de venda; 3. o direito à escolha de bens alternativos de qualidade satisfatória a preços razoáveis; e 4. o direito de ser ouvido no processo de decisão governamental.

A expansão do comércio eletrônico, a revolução da internet das coisas e a crescente internacionalização das relações de consumo (DJUROVIC; MICKLITZ, 2017) extrapolam o campo da ciência e da técnica e exigem novos arquétipos jurídicos (MARTINI, 2017). Para solucionar os problemas contemporâneos, não se pode contar apenas com o processo legislativo. A segurança das contratações e o equilíbrio do mercado dependem de iniciativas inovadoras pautadas no direito posto.

27 Acredita-se que a referência constante no documento oficial seja uma alusão à obra de Havelock Ellis, intitulada The genius of Europe, publicada em Londres, pela Williams \& Norgate, em 1950.

28 "Economic expansion is not an end in itself. Its first aim should be to enable disparities in living conditions to be reduced. It must take place with the participation of all the social partners. It should result in an improvement in the quality of life as well as in standards of living. As befits the genius of Europe, particular attention will be given to intangible values and to protecting the environment, so that progress may really be put at the service of mankind" (UNIÃO EUROPEIA, 1973). 
Para evitar uma obsolescência prematura das normas jurídicas, é preciso que elas sejam pensadas como sistemas, dotadas de elevada carga axiológica e principiológica, a fim de que o seu intérprete consiga adaptar o valor eleito pelo legislador ao caso concreto. A elevação da carga axiológica ou principiológica das normas é o que atualiza e prepara os ordenamentos jurídicos para as mudanças constantes na pós-modernidade.

Não se pode olvidar que, em uma sociedade em constante transformação, como é o caso da transformação digital ${ }^{29}$, "também o direito do consumidor necessita se apropriar de 'novos-velhos' conceitos, como confiança e vulnerabilidade, e enxergar o consumidor como o outro-eu”, um "eu” internacionalizado, sem fronteiras, em que sua pessoa virtual, seu corpo eletrônico, como prefere Rodotà $(2009$, p. 80), corre pelos quatro cantos do mundo em forma de dados: cada vez mais deve-se buscar uma harmonização das regras no plano internacional.

Como o comércio eletrônico e o uso da internet não conhecem barreiras geográficas, no plano internacional é necessário atingir um grau mínimo de compatibilidade entre os sistemas jurídicos. Na mesma medida em que o crescimento econômico não é um fim em si mesmo, deve servir para reduzir as disparidades nas condições de vida, $\mathrm{e}$ as novas tecnologias, permeadas de riscos e oportunidades, devem ser utilizadas para a melhoria das condições de vida e a eliminação da discriminação.

Como o direito certamente não pode ficar alheio a essa nova realidade, deve adaptar-se e buscar para si novos paradigmas que vão se formando, ao mesmo tempo que convive com os já presentes no tecido social e na malha de direito do consumidor.

\section{REFERÊNCIAS}

BARBA, C. 2020: la fin du e-commerce ou l'avènement du commerce connecté? Paris: Fédération E-commerce et Vente à Distance, 2011.

BERGSTEIN, L. Inteligência artificial nas práticas de geopricing e geoblocking: a tutela dos vulneráveis nos contratos eletrônicos. In: TEPEDINO, G.; SILVA, R. G. O direito civil na era da inteligência artificial. São Paulo: Revista dos Tribunais, 2020.

BERGSTEIN, L.; TRAUTWEIN, J. R. Discriminação e Diferenciação de Preços nas Relações de Consumo. Revista da Faculdade de Direito da Universidade Federal de Uberlândia (UFU), v. 47, p. 136-156, 2019. BOLGER, P. The internet of things: Cayla doll is banned in Germany over privacy and security concerns. LK Shields. 2017. Disponível em: https://www.lkshields.ie/. Acesso em: 31 ago. 2020.

29 A transformação digital pode ser definida como o conjunto de mudanças tecnológicas que tem a capacidade de influenciar todos os aspectos da vivência humana (STOLTERMAN; FORS, 2004, p. 689). 
BONATTI, A.; CISTERNAS, G. Consumer scores and price discrimination. The Review of Economic Studies, v. 87, n. 2, p. 750-791, 2020.

BOURREAU, M.; STREEL, A. de. The regulation of personalized pricing in the digital era. Paris: OCDE, 2018. Disponível em: https://www.oecd.org/competition/personalised-pricing-in-the-digital-era. htm. Acesso em: 17 ago. 2020.

BRASIL. Decreto n. 5.903, de 20 de setembro de 2006, dispõe sobre as práticas infracionais que atentam contra o direito básico do consumidor de obter informação adequada e clara sobre produtos e serviços previstas na Lei n. 8.078, de 11 de setembro de 1990. Brasília, DF, 20 set. 2006.

BRASIL. Lei n. 12.529, de 30 de novembro de 2011, estrutura o Sistema Brasileiro de Defesa da Concorrência; dispõe sobre a prevenção e repressão às infrações contra a ordem econômica, dentre outras providências. Brasília, DF, 30 nov. 2011. Disponível em: http://www.planalto.gov.br/ccivil_03/_ ato2011-2014/2011/lei/112529.htm. Acesso em: 13 ago. 2020.

BRASIL. Lei n. 13.709, de 14 de agosto de 2018, dispõe sobre a proteção de dados pessoais e altera a Lei n. 12.965, de 23 de abril de 2014 (Marco Civil da Internet). Brasília, DF, DOU de 15 ago. 2018a.

BRASIL. Ministério da Justiça. Departamento de Proteção e Defesa do Consumidor - DPDC. Processo: 08012.002116/2016-21. 18 jun. 2018b.

BRASIL. Ministério da Justiça. Departamento de Proteção e Defesa do Consumidor - DPDC. Nota Técnica n. 92/2018/CSA-SENACON/CGCTSA/GAB-DPDC/DPDC/SENACON/MJ. Disponível em: http://www.mpsp.mp.br/portal/page/portal/cao_consumidor/SENACON/SENACON_NOTA_TECNICA/SENACON\%20DECIS\%C3\%83O\%20geo\%20pricing\%20e\%20geo\%20blocking\%20multa.pdf. Acesso em: 13 ago. 2020a.

BRASIL. Ministério Público. Disponível em: https://www.mprj.mp.br/home/-/detalhe-noticia/visualizar/61905. Acesso em: 13 ago. 2020b.

BRASIL. Superior Tribunal de Justiça. Recurso Especial n. 1.479.039/MG, relator ministro Humberto Martins, $2^{\text {a }}$ Turma, julgado em 6 out. 2015.

BROWNSWORD, R. The E-Commerce Directive, consumer transactions, and the digital single market: questions of regulatory fitness, regulatory disconnection and rule redirection. In: GRUNDMANN, S. (ed.). European contract law in the digital age. Cambridge, UK: Intersentia, 2017. p. 165-204.

CAMURÇA, L. C. V. de. Sociedade de vigilância, direito à privacidade e proteção de dados pessoais: uma análise sobre a influência de técnicas de publicidade comportamental na internet no consumidor usuário. 2020. Dissertação (Mestrado em Direito) - Universidade Federal do Ceará, Fortaleza, 2020.

CARNETI, K. Boneca conectada à internet conversa com crianças e armazena informações. Exame, 19 fev. 2015. Disponível em: https://exame.com/tecnologia/boneca-conectada-a-internet-conversa-com-criancas-e-armazena-informacoes/. Acesso em: $1^{\circ} \mathrm{dez} .2020$.

CONSUMERS INTERNATIONAL. Briefing: The Internet of Things and challenges for consumer protection. Apr. 2016. Disponível em: https://www.consumersinternational.org/media/1294/briefing-connection-and-protection-the-internet-of-things-and-challenges-for-consumer-protection. pdf. Acesso em: $1^{\mathrm{o}} \mathrm{dez} .2020$. 
DATA PROTECTION WORKING PARTY. Guidelines on Automated individual decision-making and Profiling for the purposes of Regulation 2016/679. 2017. Disponível em: ec.euroepa.eu. Acesso em: 17 ago. 2020.

DECOLAR é multada em R 7,5 milhões por diferenciar preços a consumidor. Veja, 18 jun. 2018. Disponível em: https://veja.abril.com.br/economia/decolar-e-multada-em-r-75-milhoes-por-diferenciar-precos-a-consumidor/. Data de acesso: $1^{\circ} \mathrm{dez} .2020$.

DECOLAR.COMé multada em R \$ 7,5 milhões por diferenciação de preço. O Globo, 18 jun. 2018. Disponível em: https://oglobo.globo.com/economia/defesa-do-consumidor/decolarcom-multada-em-75-milhoes-por-diferenciacao-de-preco-22794582. Acesso em: $1^{\circ} \mathrm{dez} .2020$.

DJUROVIC, M.; MICKLITZ, H. W. Internationalization of Consumer Law: a game changer. Gewerbestrasse: Springer Nature, 2017.

EUROPEAN CONSUMER ORGANIZATION. Automated decision making and artificial intelligence: a consumer perspective. Bruxelles: Bureau Européen des Unions Consommateurs, 2018.

FORD, R. T. Save the robots: cyber profiling and your so-called life. Stanford Law Review, p. 1573-1584, 2000.

FRAZÃO, A. Geopricing e geoblocking: as novas formas de discriminação de consumidores. Os desafios para o seu enfrentamento. Jota, 15 ago 2018. Disponível em: https://www.jota.info/paywall?redirect to=//www.jota.info/opiniao-e-analise/colunas/constituicao-empresa-e-mercado/geopricing-e-geoblocking-as-novas-formas-de-discriminacao-de-consumidores-15082018. Acesso em: 13 ago. 2020.

FREITAS FILHO, R.; COSTA, J. P. B. da. Direitos fundamentais, direito do consumidor e igualdade: 0 caso dos "rolezinhos". Revista de Direito do Consumidor, São Paulo, v. 112, p. 321-338, jul./ago. 2017.

GINSBURG, RB. Advocating the Elimination of Gender-Based Discrimination: The 1970s New Look at the Equality Principle University of Cape Town, South Africa, 2006. [Discurso proferido em 10 de fevereiro de 2006]. Disponível em: https://www.supremecourt.gov/publicinfo/speeches/viewspeech/ sp_02-10-06. Acesso em: 30 ago. 2020.

HILDEBRANDT, M. Defining profiling: a new type of knowledge? In: HILDEBRANDT, M.; GUTWIRTH, S. Profiling the European citizen. Dordrecht: Springer, 2008. p. 17-45.

KAISER, B. Manipulados: como a Cambridge Analytica e o Facebook invadiram a privacidade de milhões e botaram a democracia em xeque. Rio de Janeiro: Harper Collins, 2020.

KOTLER, P.; KARTAJAYA, H.; SETIAWAN, I. Marketing 4.0: do tradicional ao digital. Tradução Ivo Korytowski. Rio de Janeiro: Sextante, 2017.

KOTLER, P.; KELLER, K. L. Administração de marketing. Tradução Sônia Midori Yamamoto. São Paulo: Pearson Education do Brasil, 2012.

MACAU. Grupo de trabalho para a proteção das pessoas no que diz respeito ao tratamento de dados pessoais. Parecer 05/2014 sobre técnicas de anonimização. 2014. Disponível em: https://www.gpdp. gov.mo/.Acesso em: 15 nov. 2020.

MAHESHWARI, S. Got a fever? There's an ad for that. The New York Times, 23 Oct. 2018. Disponível em: https://www.nytimes.com/2018/10/23/business/media/fever-advertisements-medicine-clorox.html?action=click\&module=Top\%20Stories\&pgtype=Homepage. Acesso em: 30 ago 2020. 
MARQUES, C. L. Contratos no Código de Defesa do Consumidor: o novo regime das relações contratuais. 8. ed. São Paulo: Revista dos Tribunais, 2019.

MARQUES, C. L.; MIRAGEM, B. Serviços simbióticos ou inteligentes e proteção do consumidor no novo mercado digital: homenagem aos 30 anos do Código de Defesa do Consumidor. Revista do Advogado sobre os "30 anos do Código de Defesa do Consumidor". (ahead of print).

MARQUES, C. L.; MUCELIN, G. Inteligência artificial e "opacidade" no consumo: a necessária revalorização da transparência para a proteção do consumidor. In: TEPEDINO, G.; SILVA, R. G. O Direito Civil na Era da Inteligência Artificial. São Paulo: Revista dos Tribunais, 2020.

MARTINI, S. R. Metateoria do Direito Fraterno e direito do consumidor: limites e possibilidades do conceito de fraternidade. Revista de Direito do Consumidor, v. 113, set./out. 2017, p. 271-295.

MICKLITZ, H.-W.et al. The fathers and mothers of Consumer Law and Policy in Europe: the foundational years 1950-1980. Fiesole, FL: European University Institute, 2019.

MIK, E. The erosion of autonomy in online consumer transactions. Law, Innovation and Technology, v. 8, n. 1, p. 1-38, 2016.

MIRAGEM, B. A internet das coisas e os riscos do admirável mundo novo. Consultor Jurídico, 29 mar. 2017. Disponível em:https://www.conjur.com.br/2017-mar-29/garantias-consumo-internet-coisas-riscos-admiravel-mundo. Acesso em: $1^{\circ} \mathrm{dez} .2020$.

MIRAGEM, B. Novo paradigma tecnológico, mercado de consumo digital e o direito do consumidor. Revista de Direito do Consumidor, São Paulo, v. 125, set./out. 2019.

MIRAGEM, B. Curso de direito do consumidor. São Paulo: Revista dos Tribunais, 2020.

ORGANISATION FOR ECONOMIC CO-OPERATION AND DEVELOPMENT. Personalised pricing in the digital era. Prepared by Pedro Gonzaga, Michael Donohue and Dries Cuijpers. Background Note by the Secretariat. DAF/COMP(2018)13. 28 November 2018.

PFEIFFER, R. A. C. Defesa da concorrência e bem-estar do consumidor. São Paulo: Revista dos Tribunais, 2015.

POEUDNIAK-GIERZ, K. Consequences of the use of personalization algorithms in shaping an offer: a private law perspective. Masaryk University Journal of Law and Technology, v. 13, n. 2, p. 161-188, 2019.

RODOTÀ, S. Data protection as a fundamental right. In: GUTWIRTH, S. et al. Reinventing data protection? Netherlands: Springer, 2009.p. 77-82.

RODOTÀ, S. Il diritto di avere diritti. Bari: Laterza, 2012.

SEARS, A. M. The limits of online price discrimination in Europe. Columbia Science \& Technology Law Review, v. 21, p. 1-42, 2019.

SENADO FEDERAL. Projeto de Lei n. 4.496. Altera a Lei n. 13.709, de 14 de agosto de 2018 (Lei Geral de Proteção de Dados Pessoais - LGPD), para definir a expressão “decisão automatizada”. Disponível em: https://www25.senado.leg.br/web/atividade/materias/-/materia/138136. Acesso em: 19 maio 2020. 
SOLON, A. Diferenciação de preços. Revista do Ibrac - Direito da Concorrência, Consumo e Comércio Internacional, São Paulo, v. 3, p. 105-116, jan. 1996.

STOLTERMAN, E; FORS, A. C. Information technology and the good life. In: KAPLAN, B.; TRUEX III, D. P.; WASTELL, D.; WOOD-HARPER, A. T.; DEGROSS, J. I. Information Systems Research: Relevant Theory and Informed Practice. Boston, Dordrecht, London, Moscow: Kluwer Academic Publishers, p. 687-692, 2004.

STUCKE, M. E.; GRUNES, A. P. Big data and competition policy. Oxford, UK: Oxford University Press, 2016. Disponível em: https://www.researchgate.net/publication/308970973. Acesso em: $1^{\mathrm{o}} \mathrm{dez}$. 2020.

SUMPTER, D. Dominados pelos números. Do Facebook às fakenews - os algoritmos que controlam nossa vida. Tradução Anna Maria Sotero e Marcello Neto. Rio de Janeiro: Bertrandt, 2019.

TEPEDINO, G.; SILVA, R. da G (coord.). O direito civil na era da inteligência artificial. São Paulo: Revista dos Tribunais, 2020.

UNIÃO EUROPEIA. Declaration of the Council of the European Communities and of the representatives of the Governments of the Member States meeting in the Council of 22 November 1973 on the programme of action of the European Communities on the environment. 1973. Disponivel em: https://eur-lex.europa.eu/LexUriServ/LexUriServ.do?uri=CELEX:41973X1220:EN:HTML. Acesso em: 2 dez. 2020.

UNIÃO EUROPEIA. Diretiva 2004/113/CE do Conselho, de 13 de Dezembro de 2004, que aplica o princípio de igualdade de tratamento entre homens e mulheres no acesso a bens e serviços e seu fornecimento. Disponível em: http://eur-lex.europa.eu/legal-content/PT/TXT/HTML/?uri=CELE$\mathrm{X}$ 32004L0113\&from=PT. Acesso em: 13 ago. 2020.

UNIÃO EUROPEIA. Regulamento (UE) 2016/679 do Parlamento Europeu e do Conselho de 27 de abril de 2016 relativo à proteção das pessoas singulares no que diz respeito ao tratamento de dados pessoais e à livre circulação desses dados e que revoga a Diretiva 95/46/CE (Regulamento Geral sobre a Proteção de Dados). Disponível em: https://eur-lex.europa.eu/legal-content/PT/TXT/HTML/?uri=CELEX:32016R0679\&from=EN. Acesso em: 2 dez. 2020.

UNITED NATIONS CONFERENCEONTRADEAND DEVELOPMENT.United Nations Guidelines for Consumer Protection. New York, Geneva: United Nations, Unctad. Disponível em: http://unctad.org/ en/PublicationsLibrary/ditccplpmisc2016d1_en.pdf. Acesso em: 5 nov. 2018.

YOUYOU, W.; KOSINSKI, M.; STILLWELL, D. Computer-based personality judgments are more accurate than those made by humans. Proceedings of the National Academy of Sciences, v. 112, n. 4, p. 1036-1040, 2015. 